ORIGINAL ARTICLE

\title{
Does long term residency near industry have an impact on the body burden of polychlorinated dibenzo-p-dioxins, furans, and polychlorinated biphenyls in older women?
}

\author{
T Pless-Mulloli, R Edwards, D Howel, R Wood, O Paepke, T Herrmann
}

Occup Environ Med 2005;62:895-901. doi: 10.1136/oem.2004.018754

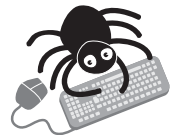

Figure 3 and tables 4 and 5 are available on the OEM website (www. occenvmed.com/ supplemental)

See end of article for authors' affiliations

\section{Correspondence to:} Dr T Pless-Mulloli, School of Population and Health Sciences, The Medical

School, Framlington Place, Newcastle upon Tyne NE2 $4 \mathrm{HH}, \mathrm{UK}$;

Tanja.Pless-Mulloli@

ncl.ac.uk

Accepted 22 June 2005
Background: For the retrospective study of environment and health linkages biomarkers of exposure are required. Polychlorinated dibenzo-dioxins and furans (PCDD/F) and polychlorinated biphenyls (PCBs) have been useful markers in some settings. This is the first study of PCDD/F body burden in a population based sample from the UK.

Aims and Methods: The authors aimed to investigate whether long term residents close to a heavy chemical industrial complex (Teesside, UK) had a higher body burden and distinct pattern of PCDD/F and PCBs. We measured current levels of PCDD/F and PCBs in a population based sample of older women (mean 64 years, range 42-79 years). Forty women were recruited, 20 living near (zone A: 0.1-2.7 km) and 20 distant (zone C: 5-40 km) from industry during 2000-03. The authors ascertained occupational exposure to lung carcinogens, residential history, consumption of local produce, breast feeding, diet, and height and weight.

Results: The mean body burden measured on lipid basis in $\mathrm{ng} / \mathrm{kg}$ for the whole sample was: WHO-TEQ (PCDD/Fs): 29.9, 2378TCDD: 4.0, PCB 118:16200, PCB156: 13100. Body burdens were similar to others reported from industrialised countries, except that mean 2378TCDD was slightly higher. Mean ages, body mass index, and lifelong dietary patterns were similar in both zones. The authors found no significant difference in mean body burden levels between zones $A$ and $C$ before or after adjustment for covariates. All congener patterns were consistent with an urban background pattern, and there was no significant difference between congener compositions in the two zones. The TCDD body burden increased with age with accelerated increments above age 70 .

Conclusion: Long term residency near heavy and chemical industry did not have an effect on women's body burden of PCDD/Fs and PCBs on Teesside, UK. The body burden of PCDD/F and PCBs was not a suitable biomarker for chronic, non-occupational exposure to industrial air pollution.
$\mathrm{R}$ etrospective exposure assessment poses a major challenge for environmental epidemiology studies. Occupational and residential histories, environmental measurement data, and descriptive (non-measurement) data are crucial for this process. ${ }^{1}$ Often the characterisation and measurement of past exposure uses relatively crude methods such as personal recall of work or residential histories or estimates via modelling, often extrapolated from environmental measurements limited in scope and time period.

The use of biological samples (biomarkers) as indicators of internal exposure, early biological effect, or susceptibility has widened the scope of retrospective exposure assessment in environmental epidemiology. A good biomarker should be specific for the environmental exposures of interest, or an adequate proxy, and be readily obtainable from members of the community of interest. ${ }^{2}$ Biomarkers have the advantage of taking into account all routes of exposure (inhalation, dermal, oral), and providing an estimate of a subject's actual body burden or dose of exposure rather than the proxy measure of levels in the environment. A biomarker could act as a measure of long term exposure if it has a sufficiently long half life in the human body, even though it will be subject to damping that is a reduction in exposure variability. ${ }^{3}$ However, use of biomarkers for long term exposure assessment has been limited because the biological half life of most potential biomarkers is measured in hours or days rather than years. ${ }^{13}$

Polychlorinated dibenzo-p-dioxins and furans (PCDD/Fs) and polychlorinated biphenyls (PCBs) are possible biomarkers for medium to long term exposure as the half lives of congeners range from 3-20 years. ${ }^{4}$ Specific high dose PCDD/F exposures such as those from contaminated Agent Orange spraying (1962-70) during the Vietnam war, from 2378 tetra-chlorodibenzo-dioxin (2378 TCDD) released in Seveso, Italy in 1976, and in the "Khimprom" incident in Russia have remained evident in body burden measurements of those exposed up to over 25 years later. ${ }^{5-8}$ Examples for PCBs include the Yu-cheng incident in Taiwan' and Mohawk women living near hazardous waste sites. ${ }^{10}$

This raised the possibility that people living close to established industrial sources of PCDD/F emissions may also show increased levels and distinct patterns of PCDD/Fs especially as some of the industry types on Teesside (steel making, coke ovens, incineration) are known to carry the potential for emitting PCDD/F. Such differences in congener pattern have been a useful tool for source identification in some settings, such as New York City ${ }^{5}$ and for PCB in the breast milk of Mohawk women whose congener patterns in breast milk resembled those from caught perch near a waste site. ${ }^{11}$

The findings from studies contrasting PCDD/F body burden levels in people living close to and distant from incinerators have been variable with only a few of them finding such differences. ${ }^{812-15}$ It is estimated that around $90 \%$ of the intake

Abbreviations: $\mathrm{PCB}$, polychlorinated biphenyls; $\mathrm{PCDD} / \mathrm{Fs}$, polychlorinated dibenzo-p-dioxins and furans (PCDD/Fs) 
of PCDD/Fs in the general population derives from food intake. ${ }^{16}{ }^{17}$ Therefore we consider it essential to have covariate information on age, diet, body mass index, and breast feeding history to aid interpretation of body burden data. In addition, women reduce their body burden of PCDD/F during breast feeding. However, such information on covariates has only been collected by very few studies. ${ }^{12}{ }^{13} 18-20$

It is less clear how much occupational and environmental sources contribute to the body burden of PCDD/Fs. ${ }^{516} 172122$ There are also no studies so far which have investigated PCDD/F body burden as proxy of exposure to a mixture of industrial emissions while controlling in detail for local food consumption and breastfeeding over several decades.

General population based data on the body burden of PCDD/F in human blood samples are available from the United States, Canada, Germany, France, Finland, Taiwan, and Spain. ${ }^{163-25}$ Most of these samples were from male subjects and the average ages ranged between 20 s and 50 s. No human body burden data are available for older female populations, whereas human breast milk samples have been used to document variation between countries and the downwards time trends in younger women. ${ }^{23}$

The study reported here had two objectives. Firstly, to document current levels of PCDD/Fs and PCBs in a population based sample of older women from the UK and compare those to others reported in the literature. Secondly, we assessed whether women with long term residence close to an industrial complex have a higher body burden and a distinct pattern of PCDD/Fs and PCBs.

\section{THE SETTING}

Steel, heavy engineering, and chemical industries have dominated the economy in Teesside for many decades. By the middle of the 20th century this was one of the most heavily industrialised regions of Western Europe. ${ }^{26}$ Industry and housing were and still are often in close proximity resulting in potential for long term exposure to air pollution. A survey of land use since 1900 showed that housing areas which were closest to industry in the 1990s had also been closest for 40 years or more. ${ }^{27}$ Annual reports of Medical Officers of Health (MOH) from the 1920s to 1970s repeatedly emphasised the impact of industrial emissions on population health.

When systematic local authority air quality monitoring in Teesside expanded in the early 1960s, it concentrated on smoke as an indicator for fine suspended particles, sulphur dioxide, insoluble deposits, and ferric oxide. Between the 1960s and 1990s higher smoke levels were found consistently at monitoring locations in close proximity to industry. Although overall pollution levels declined drastically during this period, ${ }^{28}$ the decline in areas closest to the main industrial sites lagged several years behind other parts of the conurbation. Dispersion modelling suggested that spatial variations in ambient air pollution remained until the 1990s. This led us to hypothesise that environmental exposures including $\mathrm{PCDD} / \mathrm{F}$ were higher over many decades for residents living close to industry on Teesside. Here we explore whether such increased environmental exposure are reflected in current $\mathrm{PCDD} / \mathrm{F}$ body burden.

\section{METHODS \\ Design}

We carried out an observational study of 20 women living near and 20 women living distant from an industrial complex on Teesside, UK.

\section{Subjects}

Subjects were recruited into the body burden study from among the participants of a case control study of residential exposure to air pollution and lung cancer in females. The literature does not suggest that PCDD/F exposure is a risk factor for lung cancer, so both cases and controls were recruited into the body burden study.

In the case control study, eligible cases were women with incident primary lung cancer aged less than 80 years currently resident in Teesside and not too unwell. For the main case control study we aimed to recruit two population based controls per case, drawn at random from the Teesside population. The sampling frame was based on the regional register of all those registered with the health service. Exclusion criteria for controls mirrored those for the cases with the addition that controls with a history of lung cancer were ineligible. We selected at random two index controls per case matched by five year age group, and reserve controls for each index control from the same age group and electoral ward. If the invited index control did not want to take part, or did not reply, we approached additional reserve controls.

Residences were assigned to predefined exposure zones: $\mathrm{A}=$ near $(0.1-2.7 \mathrm{~km}), \mathrm{B}=$ intermediate (no subjects from zone $\mathrm{B}$ are included in this body burden study), $\mathrm{C}=$ distant from industry $(5-40 \mathrm{~km}$ ) (see fig 1). The definition of zones was informed by land use surveys, dispersion modelling, and monitoring ${ }^{26} 28$ and was refined based on the findings of two previous studies. Ambient exposures to air pollution in zone A had been much higher than the other zones in until the 1980s.

For the body burden study we recruited 20 women from zone A ( 10 cases and 10 controls) and 20 from zone C ( 10 cases and 10 controls) sequentially between January 2000 and December 2003. This involved screening for eligibility and asking all eligible women to participate in the body burden study at the time of their interview for the case control study. This continued until 10 subjects within each of the four groups (cases zone A; controls zone A; cases zone C; controls zone C) were recruited. Women with weight loss of $\geqslant 3.5 \mathrm{~kg}$ over last three months were excluded because of the potential for weight loss to affect PCDD/F levels which are reported on a per lipid basis. We also excluded women who had worked for at least one year in heavy industry within the last 20 years or who had lived for less than 30 years in total and 10 years consecutively in their current zone. This was in order to avoid contamination from occupational exposure and to maximise the difference in the history of exposure to industrial emissions between the two groups.

We approached 102 women to recruit 20 cases. The reasons for non-inclusion were: too ill (3), significant weight loss (44), resident in current zone for less than 10 years consecutively and/or less than 30 years in total (27), refusers (4), occupational exposure (1), too ill plus significant weight loss (1), reason not recorded (2). We approached 55 women to recruit 20 controls. The reasons for non-participation were: too ill: 0, significant weigh loss (14), resident in zone for less than 10 years consecutively and/or less than 30 years in total (16), refusers (1), occupational exposure (1), reason not recorded (3).

\section{Data collection}

Information was collected by interview using a structured questionnaire on: current and past consumption of local animal and vegetable produce; number and length of breast feeding periods; current and typical diet; and self reported height and weight. Information on lifelong occupational history and place of residence was available from the original interview conducted for the case control study. The questionnaire was administered by a research nurse at the time of the collection of the blood sample. Whole blood (40-60 ml) was analysed for PCDD/Fs and PCBs. 


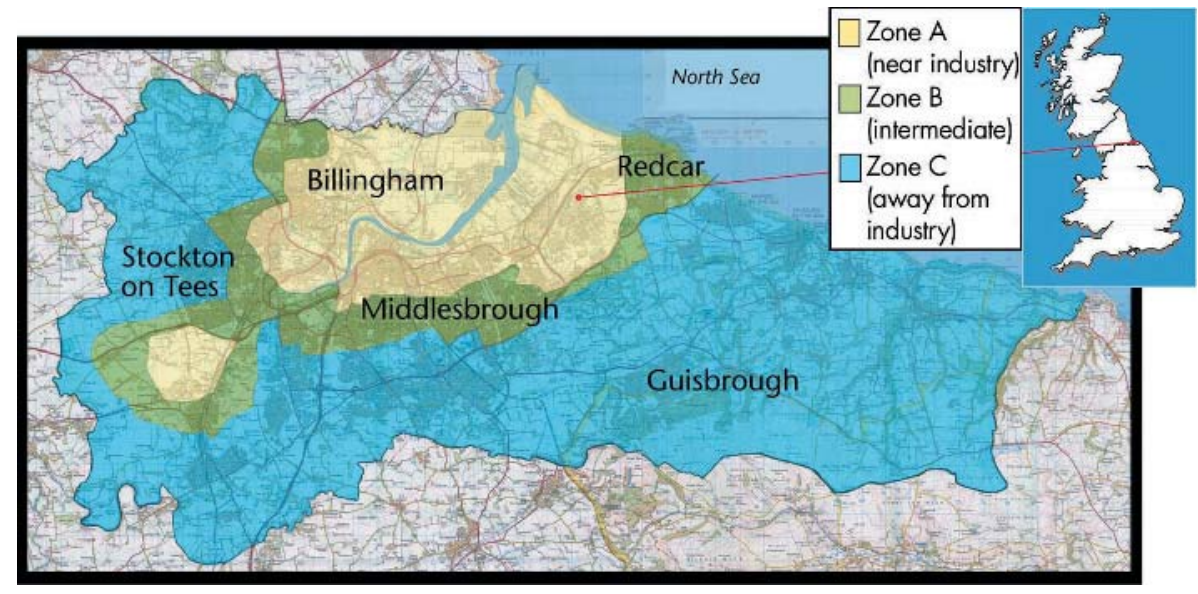

Figure 1 Study areas.

\section{Analysis of samples for PCDD/Fs and PCBs}

An aliquot of the sample was spiked with ${ }^{13} \mathrm{C}_{12}$ labelled internal standards (17 PCDD/Fs, 12 dioxin-like PCBs). PCDD/ Fs, PCBs, and lipids were extracted using solid/fluid extraction. After addition of water/ethanol, the blood sample was introduced to a chem-elute solid phase column and extracted with n-hexane/isopropanole. The lipid concentration was determined gravimetrically. The clean up of sample extracts used a combination of multicolumns applying neutral, acidic, and basic silica, florisil, and activated carbon (AX21). PCDD/F and PCB measurement was done on a VG AutoSpec High Resolution Mass Spectrometer (HRGC/HRMS) on a silica column (DB 5). Two isotope masses were measured for each congener. The isotope dilution method was used for identification and quantification. The recovery standard used was 1234 TCDD $\left({ }^{13} \mathrm{C}_{12}\right)$.

\section{Data analysis}

We report results in $\mathrm{ng} / \mathrm{kg}$ on lipid base. The main comparison of interest was between all (cases and controls combined) residents of zones A and C. However, we verified that there was no evidence that body burden levels differed in cases and controls, or if there was an interaction between

Table 1 Characteristics of the study population

\begin{tabular}{|c|c|c|c|c|}
\hline & \multicolumn{2}{|c|}{$\begin{array}{l}\text { Zone A (near } \\
\text { industry) } \\
(\mathrm{n}=20)\end{array}$} & \multicolumn{2}{|c|}{$\begin{array}{l}\text { Zone } C \text { (distant from } \\
\text { industry) }(n=20)\end{array}$} \\
\hline & Mean & Median & Mean & Median \\
\hline Age (years) & 62.5 & 65.0 & 65.3 & 67.0 \\
\hline Body mass index $\left(\mathrm{kg} / \mathrm{m}^{2}\right)$ & 28.7 & 27.9 & 27.9 & 28.7 \\
\hline Breast feeding (months) & 3.3 & 0 & 4.5 & 0 \\
\hline \multicolumn{5}{|l|}{$\begin{array}{l}\text { Lifelong dietary consumption of } \\
\text { (number of portions } \times 1000 \text { ) }\end{array}$} \\
\hline Meat & 16.0 & 16.7 & 18.3 & 19.1 \\
\hline Fish & 6.0 & 5.3 & 4.4 & 5.0 \\
\hline Dairy products & 39.3 & 40.4 & 41.8 & 40.8 \\
\hline Eggs & 8.9 & 5.9 & 8.6 & 5.9 \\
\hline $\begin{array}{l}\text { Years in occupations considered } \\
\text { a high risk for lung cancer } \\
\text { (years) }\end{array}$ & 1.6 & 0 & 1.0 & 0 \\
\hline $\begin{array}{l}\text { Continued residence in last } \\
\text { zone (years) }\end{array}$ & 47.3 & 45.5 & 40.5 & 38.0 \\
\hline \multicolumn{5}{|l|}{$\begin{array}{l}\text { Consumption of local produce } \\
\text { from zone } A \text { (years) }\end{array}$} \\
\hline Vegetables & 12.7 & 4.5 & 0.4 & 0 \\
\hline Animal products & 2.3 & 0 & 0 & 0 \\
\hline $\begin{array}{l}\text { Total residence in last zone } \\
\text { (years) }\end{array}$ & 52.6 & 49.0 & 44.2 & 40.5 \\
\hline
\end{tabular}

case status and zone. Since this was so ( $p>0.4$ for all tests), the later comparisons of body burdens in zones $\mathrm{A}$ and $\mathrm{C}$ were unlikely to be biased by having half of the sample in each zone from lung cancer cases.

The mean PCDD/F and PCB levels were compared in zones $A$ and $C$ and 95\% confidence intervals for the difference in means were estimated. We also reported the means of individual congeners and compared them between zones A and C. We calculated bootstrap confidence intervals for those variables where the distributions were apparently nonnormal PCB118, 1234678 Hepta-CDD, and OCDD. Further comparisons of mean levels were made using multivariate linear regression after adjusting for covariates using forward stepwise estimation. Covariates chosen a priori were known determinants of PCDD/F and PCB levels identified from the literature (age and age squared, body mass index, cumulative dietary intake of eggs, fish, meat, and dairy products, consumption of local vegetable produce, breast feeding duration, and occupational exposure to lung carcinogens). The relation between 2378 TCDD and age was illustrated in a plot with locally weighted scatter plot smoothing (lowess).

The descriptive analysis of congener patterns, that is the proportions rather than the total amounts of ach congener in a sample used numerical summary statistics, and a graphical display via principal components analysis. This technique produces new variables which are uncorrelated linear combinations of the original variables that explain decreasing amounts of the total variation. Therefore a plot of the first few new variables will capture most of the information in the full set. A formal comparison of the composition of samples

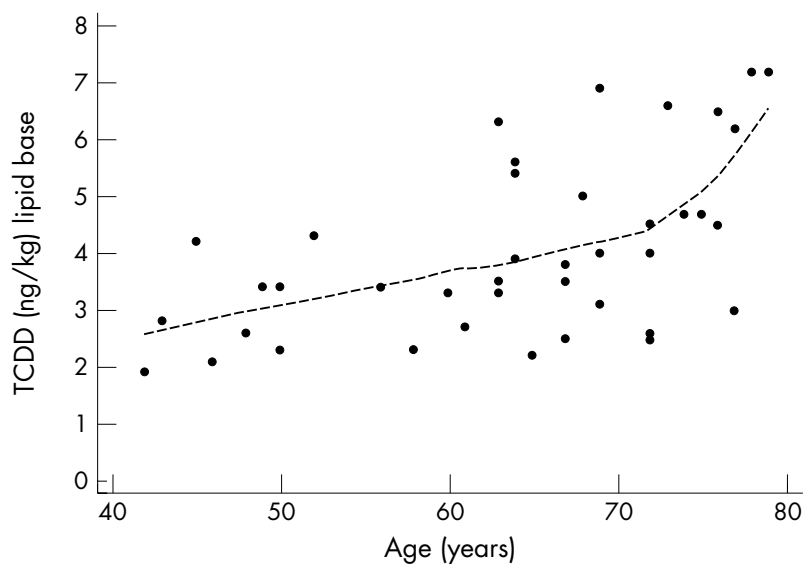

Figure 2 Relation between age and TCDD $(\mathrm{ng} / \mathrm{kg})$ lipid base. 
Table 2 Mean body burden of PCDD/Fs and selected PCBs in zones A (near industry) and $C$ (away from industry) in $\mathrm{ng} / \mathrm{kg}$ lipid base

\begin{tabular}{|c|c|c|c|c|}
\hline & $\begin{array}{l}\text { Full sample, } \\
\text { mean (SD) }\end{array}$ & Zone A & Zone C & $\begin{array}{l}\text { Difference in means: } \\
\mathrm{A}-\mathrm{C}(95 \% \mathrm{Cl})\end{array}$ \\
\hline $\begin{array}{l}\text { WHO-TEQ (DF+PCB)* } \\
\text { WHO-TEQ (D)† } \\
\text { WHO-TEQ (F) } ~ \\
\text { WHO-TEQ (DF) } \\
\text { WHO-TEQ (PCB) } \\
\text { I-TEQ } \\
\text { PCB } 118 \\
\text { PCB } 156 \\
\text { PCB } 118: 156 \\
\text { Sample size }\end{array}$ & $\begin{array}{c}47.0(15.3) \\
21.1(6.8) \\
8.7(3.1) \\
29.9(9.7) \\
17.1(6.5) \\
26.0(8.4) \\
16200(9900) \\
13100(4280) \\
1.3(0.7) \\
40\end{array}$ & $\begin{array}{r}45.3 \\
20.7 \\
8.4 \\
29.1 \\
16.3 \\
25.4 \\
14000 \\
13200 \\
1.2 \\
20\end{array}$ & $\begin{array}{c}48.6 \\
21.6 \\
9.1 \\
30.8 \\
17.9 \\
26.5 \\
18400 \\
13000 \\
1.4 \\
20\end{array}$ & $\begin{array}{l}-3.3(-13.2 \text { to } 6.7) \\
-1.0(-5.3 \text { to } 3.4) \\
-0.7(-2.7 \text { to } 1.3) \\
-1.7(-8.0 \text { to } 4.6) \\
-1.7(-5.9 \text { to } 2.6) \\
-1.2(-6.6 \text { to } 4.2) \\
-440(-10900 \text { to } 1300 \\
-200(-2600 \text { to } 3000) \\
-0.2(-0.7 \text { to } 0.3)\end{array}$ \\
\hline $\begin{array}{l}{ }^{*} \mathrm{DF}=\mathrm{PCDD} / \mathrm{Fs} \\
+\mathrm{t}=\mathrm{PCDD} \\
\neq \mathrm{F}=\mathrm{PCDF}\end{array}$ & & & & \\
\hline
\end{tabular}

from those living in zones $\mathrm{A}$ and $\mathrm{C}$ was made using multivariate analysis of variance (MANOVA). All analyses of congener composition used log ratio transformations. ${ }^{29}$

\section{RESULTS}

Table 1 shows the characteristics of the study population. The mean age of participants from zone A was 62.5 years; the mean age of participants from zone C was 65.3 years, showing that the populations sampled were older than those in all previous population based studies. Participants in zones $\mathrm{A}$ and $\mathrm{C}$ were similar with regards to their height, weight, body mass index, breast feeding history, and occupational exposure. Breast feeding rates were low: $45 \%$ of women in both zones had ever breast fed. Lifelong consumption of meat, fish, dairy products, and eggs were similar in both zones. Zone A residents were more likely to report regularly consuming local vegetable produce from zone A. Only five individuals regularly ate animal products produced in zone A, and, four of those had only eaten such produce regularly for less than five years in total. The mean duration of continuous residence in their current exposure zone was 47.3 years for zone A residents and 40.5 years for zone $\mathrm{C}$ residents. Despite the fact that these covariates had been identified as likely determinants of body burden levels, the correlation between any of the body burden measures and the covariates was weak $(r<0.25$ for food consumption measures and BMI; $r<0.4$ for length of breast feeding). The exception was the relation with age which is shown later.

Figure 2 shows the relation between 2378 TCDD and age. Levels continued to increase until age 80 with greater rates of increase over age 70. This observation was also made for other measures of body burden.

Table 2 shows selected results of the summary measures of body burden of PCDD/Fs and PCBs in all samples, and separately for those from zones A and C. The mean body burden was slightly lower in those nearer industry for the majority of indicators, but we found no significant difference between the means of any of the indicators between participants from zones A and C. Despite the relatively small sample size, the width of the confidence intervals showed that the data were not consistent with large differences between mean levels for most variables, but would support either a large or a zero difference in PCB118 levels between residents of the two zones. After adjusting for potential covariates via multivariate linear regression, only minimal changes occurred to the estimates of the difference between means. This was because most covariates were only weakly correlated with body burden in our sample, and had similar distributions in both zones.

Table 3 shows results for individual congeners. As with the summary body burden measures, the width of the confidence intervals showed that the data were not consistent with large differences between mean levels for most congeners. The only exception was octa-chloro-dibenzo-dioxin (OCDD) where mean levels were higher further away from industry. However, the fact that the zones have been compared on so many body burden measures should be taken into account when interpreting these results.

All congener patterns were dominated by OCDD ( $>60 \%$ in all samples). Table 4 (available online at http://www. occenvmed.com/supplemental) shows the average congener

Table 3 Mean body burden of PCDD/F congeners in zones A (near industry) and C (away from industry) in $\mathrm{ng} / \mathrm{kg}$ lipid base

\begin{tabular}{lcccc}
\hline & $\begin{array}{c}\text { Full sample, } \\
\text { mean (SD) }\end{array}$ & Zone A & Zone C & $\begin{array}{l}\text { Difference in means: } \\
\mathbf{A}-\mathbf{C}(95 \% \text { Cl) }\end{array}$ \\
\hline 2378 Tetra-CDD & $4.0(1.5)$ & 4.0 & 4.1 & $-0.2(-1.2$ to 0.8$)$ \\
12378 Penta-CDD & $10.8(3.1)$ & 10.7 & 10.8 & $-0.2(-2.2$ to 1.8$)$ \\
123478 Hexa-CDD & $9.2(4.7)$ & 8.4 & 10.1 & $-1.7(-4.7$ to 1.2$)$ \\
123678 Hexa-CDD & $44.2(16.2)$ & 42.7 & 45.7 & $-3.0(-10.6$ to 7.8$)$ \\
123789 Hexa-CDD & $6.0(2.1)$ & 5.6 & 6.4 & $-0.8(-2.2$ to 0.5$)$ \\
1234678 Hepta-CDD & $30.6(26.8)$ & 21.5 & 39.8 & $-18.2(-31.5$ to 0.2$)$ \\
Octa CDD & $571(365)$ & 457 & 685 & $228(12$ to 467$)$ \\
23478 Penta CDF & $14.1(5.3)$ & 13.7 & 14.5 & $-0.8(-4.3$ to 2.6$)$ \\
234678 Hexa CDF & $4.2(4.7)$ & 3.9 & 4.5 & $-0.6(-2.5$ to 1.3$)$ \\
123478 Hexa CDF & $7.6(2.8)$ & 7.3 & 7.9 & $-0.6(-2.4$ to 1.2$)$ \\
123678 Hexa CDF & $5.4(2.0)$ & 5.2 & 5.5 & $-0.4(-1.7$ to 1.0$)$ \\
Sample size & 40 & 20 & 20 & \\
\hline \\
Values of 1234678 Hepta-F below detection limits for $>50 \%$ samples and for $>90 \%$ samples of 2378 Tetra-F, \\
12378 Penta-F, 123789 Hexa-F, 1234789 Hepta-F, and OCDF.
\end{tabular}


profile for those congeners where less than one third of samples were below detection limits: further analyses were only performed on the 10 congeners therein. The OCDD dominated patterns were consistent with an urban background pattern dominated and did not show distinctive patterns which could indicate impact from localised industrial sources.

The first two principal components based on proportions of each congener retained $88 \%$ of the sample variation; therefore little information was lost by only plotting the first two components. This plot (fig 3; see http://www.occenvmed. com/supplemental) showed that there was some tendency for the congener patterns from samples in zone A to be low on the first component and higher on the second component (left and top of diagram), whereas congener patterns from samples in zone $\mathrm{C}$ were higher in the first component and lower in the second component (bottom right). However, there was no clear separation, suggesting that they differed only slightly in congener profile or composition. The hypothesis that the mean composition vectors were equal in samples from zone $\mathrm{A}$ and zone $\mathrm{C}$ was tested via MANOVA and could not be rejected $(\mathrm{p}=0.33)$.

\section{DISCUSSION}

This was a population based study with much detail on residential and food consumption information. It presents the first population based dataset of body burden data for PCDD/Fs and PCBs for the UK.

The dearth of data from older women complicated comparisons with data from other studies. We observed that the shape of the relation between body burden of 2378 TCDD and age is consistent with a more than linear increase after the age of about 70: an observation made for the first time. We do not know whether this observation could reflect specific patterns of exposure in Teesside or would be observed in older people from other areas. Given the low rates of breast feeding in this study we consider it justified to compare levels in this female cohort with levels in males from other studies. These are shown in table 5 (see http://www.occenvmed/ supplemental) for studies from 1990 onwards and for populations with a mean age of 40 and over or if the range of ages included 40+. The levels of the body burden of PCDD/ Fs and PCBs measured as toxicity equivalents in this older female UK population in 2002-03 were lower than those reported from Canada, Finland, the United States, and Germany. ${ }^{180-32}$ I-TEQs were similar to studies from Spain and Japan. ${ }^{33}{ }^{34}$ However, all of these studies had lower mean ages compared to our study. In contrast, TEQs in our UK based study were higher than those for blood donors from Spain in 1993 (age 19-55 years), ${ }^{35}$ controls in the Time Beach incinerator study (age 18-64 years), ${ }^{13}$ a general population sample from Germany in $1996^{16}$ (mean age 49 years), a Taiwanese control group from an incinerator study (age 5665 years $)^{15}$ and much higher than the recently (2001) reported levels from Vientiane in Laos. ${ }^{36}$

Although there was no indication in this older female population that the body burden measured as toxicity equivalent was unusual compared with other industrialised countries, the mean levels of 2378 TCDD in both groups in our study were relatively high (4.0 ng/kg WHO-TEQ) compared with those in other recently measured populations $^{15} 3233353738$ ). We are not aware of an environmental exposure to 2378 TCDD that could have affected our residents both in zones $\mathrm{A}$ and $\mathrm{C}$ and therefore this finding remains unexplained. The fact that our study population had lived in their current zone of residence for an average of over 40 years suggests that the explanation for these relatively high 2378 TCDD levels lies in environmental and/or lifestyle factors common to women of this age group in the area. On the other hand it could simply be a consequence of the higher average age of our sample.

The hypothesis-that long term residents close to an industrial complex have a higher body burden and show a distinct pattern of PCDD/F and PCBs-was not upheld in this UK setting. Those living nearby had long term residential exposure to general (as opposed to specific) heavy industry environmental pollution. However, the body burden of these biomarkers did not detect a difference in level and pattern between those living near and far away. Other studies have found higher levels of dioxins in those living close to industry. Orloff et al reported that of 28 residents who lived in an area with a concentration of chemical industry plants, 14 exceeded the 95th percentile for PCDD/F of an age matched comparison population. ${ }^{32}$ Fierens et al compared PCDD/F body burden in rural and urban residents living close to incinerators and a control group. ${ }^{19}$ They found increased body burdens of PCDD/F in rural residents who lived close to an incinerator and consumed more local produce. In contrast to the results from the study by Fierens et al our study participants did not eat much locally produced animal produce. This is likely to mean that their oral PCDD/F uptake will be dominated by the lipid uptakes from supermarket foods. ${ }^{19}$ Orloff et al reported increased levels only in older residents near heavy chemical industry and suggested that this means that higher dioxin exposure had only happened in the distant past. ${ }^{32}$ However, the majority of studies of PCDD/F body burden around incinerators has been negative. ${ }^{8}{ }^{12-15}$ There were also positive findings in studies that followed people exposed to Agent Orange, and the Seveso and "Khimprom" incident, which were shorter but more intensive exposures compared to those in our UK setting.

There were several possible explanations for the lack of difference between levels in subjects living near and far from the industrial complex. One possible explanation was that the intake of PCDD/F and PCB via background food consumption was such a dominant source of exposure that impacts from local industrial sources were undetectable, if they existed. Alternatively and/or additionally, differential exposures due to proximity of residence near industry may only have occurred in the more distant past, with more recent exposure experience being similar, the result of changes in emissions and industrial processes. Finally, PCDD/F and PCB exposure may truly have been similar in zone A and zone $\mathrm{C}$ residents, as opposed to air pollution levels, which are known to have differed in the past.

Although the UK does not currently have any population based body burden data for PCDD/F it is known to have rich data sets for food from regular National Total Diet studies as well as part of EU food surveillance. ${ }^{39}$ These show that PCDD/ $F$ levels in UK foods are comparable to levels in other European countries. This would suggest that the body burden of UK residents in the general population is likely to be similar to other European counties.

Strengths of this investigation included the very detailed residential histories and data on potential confounding exposures, the use of stringent inclusion and exclusion criteria, and the stability of the study population. Weighing up the potential for bias on our findings when combining cases and controls together in zones $\mathrm{A}$ and $\mathrm{C}$ we argue that this would be of concern if PCDD/F was strongly predictive of lung cancer, which is not the case. Another potential selection bias is related to the need to exclude women experiencing significant weight loss. We have provided body burden data for PCDD/F and PCBs from the UK general population for the first time. However, we acknowledge that the relatively small number of samples was a weakness and it remains uncertain how far our findings can be generalised outside of Teesside to other UK populations. 


\section{Main messages}

- Body burdens of PCDD/F and PCBs were similar to others reported from industrialised countries, except that mean TCDD was slightly higher.

- There was no significant difference in mean body burden of PCDD/F and PCB between women living near and away from heavy industry.

- All congener patterns were consistent with an urban background pattern, and there was no significant difference between congener compositions in those living near or away from heavy industry.

- The TCDD body burden increased with age with accelerated increments above age 70 .

\section{Policy implications}

- There was no evidence to suggest that the body burden of $P C D D / F$ and $P C B$ s is a suitable biomarker for chronic, non-occupational exposure to industrial air pollution in older women in Teesside, UK.

- The observed increase in the body burden of TCDD above age 70 should be investigated further.

\section{CONCLUSIONS}

This study provides the first population based data on body burden for PCDD/F and PCB from the UK, and also from an older population than previous studies. Long term residency near heavy and chemical industry was not reflected in women's current body burden of PCDD/Fs and PCBs in the setting of Teesside UK. No evidence suggested that the body burden of PCDD/F and PCBs was a suitable biomarker for chronic, non-occupational exposure to industrial air pollution in older women in Teesside.

\section{ACKNOWLEDGEMENTS AND FUNDING}

We are grateful to the study participants, Drs Harry Gribbin and Richard Harrison for their invaluable support, research nurse Sharon Lawson-Lowe for administering the interviews and taking blood samples; Lynn Doherty for providing administrative support; "Fight against cancer in Teesside Trust", Tees Health Authority, and James Cook University Hospital Lung Fund for providing funding.

\section{Authors' affiliations}

T Pless-Mulloli, D Howel, R Wood, School of Population and Health Sciences, University of Newcastle upon Tyne, UK

R Edwards, Evidence for Population Health Unit, School of Epidemiology and Health Sciences, The Medical School, Manchester University, Manchester, UK

O Paepke, T Herrmann, ERGO Research Laboratory, Hamburg, Germany

Ethics: the protocol for this study was approved by the local research ethics committees. Participants gave informed consent and were fed back their individual results if this was requested.

\section{REFERENCES}

1 Ahrens W, Stewart P. Retrospective exposure assessment. In: Nieuwenhuijsen $M$, ed. Exposure assessment in occupational and environmental epidemiology. Oxford: Oxford University Press, 2003: 103-32.

2 Metcalf S, Orloff K. Biomarkers of exposure in community settings. J Toxicol Environ Health 2004;67:715-26.

3 Nieuwenhuijsen M, Droz P. Biological monitoring. In: Nieuwenhuijsen M, ed. Exposure assessment in occupational and environmental epidemiology. Oxford: Oxford University Press, 2003:167-80.
4 Flesch-Janys D, Becher $H$, Gurn P, et al. Elimination of polychlorinated dibenzo-p-dioxins and dibenzofurans in occupationally exposed persons. $J$ Toxicol Environ Health 1996;47:363-78.

5 Schecter A, Paepke O, Pavuk M, et al. Exposure assessment: measurement of dioxins and related chemicals in human tissues. In: Arnold Schecter TAG, ed. Dioxins and health. New Jersey: Wiley-Interscience, Hoboken, 2003c:629-78.

6 Schecter A, Tong H, Monson S, et al. Adipose tissue levels of 2,3,7,8-TCDD in Vietnamese adults living in Vietnam, 1984-87. Chemosphere 1989;18:1057-62.

7 Weiss J, Paepke O, Bignert A, et al. Concentrations of dioxins and other organochlorines (PCBs, DDTs, HCHs) in human milk from Seveso, Milan and a Lombardian rural area in Italy: a study performed 25 years after the heavy dioxin exposure in Seveso. Acta Paeditr 2003:92:467-72.

8 Schecter A, Ryan J, Paepke O, et al. Elevated dioxin levels in the blood of male and female Russian workers with and without chloracne 25 years after phenoxyherbicide exposure: The UFA "Khimprom" incident. Chemosphere 1993;27:253-8.

9 Lung S, Guo Y, Chang H. Serum concentrations and profiles of polychlorinated biphenyls in Taiwan Yu-cheng victims twenty years after the incident. Environ Pollut 2005; 136:71-9.

10 Fitzgerald $E$, Hwang $S$, Langguth $K$, et al. Fish consumption and other environmental exposures and their associations with serum $\mathrm{PCB}$ concentrations among Mohawk women in Akwesasne. Environ Res 2004:94:160-70.

11 Hwang $S$, Yang B, Fitzgerald $E$, et al. Fingerprinting $P C B$ patterns among Mohawk women. J Expo Anal Environ Epidemiol 2001;11:184-92.

12 Deml E, Mangelsdorf I, Greim H. Chlorinated dibenzodioxins and dibenzofurans (PCDD/F) in blood and human milk of non occupationally exposed persons living in the vicinity of a municipal waste incinerator. Chemosphere 1996;33:1941-50

13 Evans R, Shadel B, Roberts D, et al. Dioxin incinerator emissions exposure study Times Beach, Missouri. Chemosphere 2000;40:1063-74.

14 Gonzalez C, Kogevinas M, Gadea E, et al. Increase of dioxin blood levels over the last 4 years in the general population in Spain. Epidemiology $2001 ; 12: 365$.

15 Chen $\mathbf{H}$, Su H, Liao P, et al. Serum PCDD/F concentration distribution in residents living in the vicinity of an incinerator and its association with predicted ambient dioxin exposure. Chemosphere 2004;54:1421-9.

16 Paepke O. PCDD/PCDF: Human background data for Germany, a 10-year experience. Environ Health Perspect 1998;106(Supplement 2):723-31.

17 Buckley-Golder D. Compilation of EU Dioxin Exposure and Health Data Summary Report. Culham: AEA Technology plc for European Commission DG Environment UK department of the Environment Transport and the Regions (DETR), 1999:29

18 Cole D, Kearney J, Ryan J, et al. Plasma levels and profiles of dioxin and dioxin-like compounds in Ontario Great Lakes anglers. Chemosphere 1997; $34: 1401-9$

19 Fierens $\mathrm{S}$, Mairesse $\mathrm{H}$, Hermans $\mathrm{C}$, et al. Dioxin accumulation in residents around incinerators. IJ Toxicol Environ Health 2003;66:1287-93.

20 Goldman L, Harnly M, Flattery J, et al. Serum polychlorinated dibenzo-p-dioxins and polychlorinated dibenzofurans among people eating contaminated homeproduced eggs and beef. Environ Health Perspect 2000;108:13-19.

21 Schecter A, Quynh H, Pavuk M, et al. Food as a Source of Dioxin Exposure in the Residents of Bien Hoa City, Vietnam. J Occup Environ Med 2003;45:781-8.

22 Pless T, Schneider F, Steiner M, et al. Impact of body-mass-index and age on the blood-concentration of PCDD/PCDF of adults and children. Chemosphere 1993;26:1109-18.

23 Buckley-Golder D. Compilation of EU Dioxin Exposure and Health Data Task 5-Human Tissue and Milk Levels. Culham: AEA Technology plc for European Commission DG Environment UK department of the Environment Transport and the Regions (DETR), 1999:40.

24 Aylward L, Hays S. Temporal trends in human TCDD body burden: Decreases over three decades and implications for exposure levels. J Expo Anal Environ Epidemiol 2002;12:319-28.

25 Chen $\mathrm{H}$, Liao P, Su H, et al. Profile of PCDD/F levels in serum of general Taiwanese between gender, age and smoking status. Sci Total Environ 2005;337:31-43

26 Pless-Mulloli T, Phillimore P, Moffatt S, et al. Lung cancer, proximity to industry, and poverty in Northeast England. Environ Health Perspect 1998; 106:189-96.

27 TEES Teesside Environmental Epidemiology Group. Health, illness, and the environment in Teesside and Sunderland. Newcastle upon Tyne: University of Newcastle upon Tyne, 1995. ISBN 0-7017-0064-5.

28 Pless-Mulloli T, Dunn C, Sharp L, et al. Is it feasible to construct a community profile of exposure to industrial air pollution? Occup Environ Med 2000;57:542-9.

29 Aitchison J. The statistical analysis of compositional data. London: Chapman and Hall, 1986.

30 Kontsas H, Rosenberg C, Tornaeus J, et al. Exposure of workers to 2,3,7,8sustituted polychlorinated dibenzo-p-dioxin (PCDD) and dibenxofuran (PCDF) compounds in sawmills previously using chlorophenol-containing antistain agents. Arch Environ Health 1998;53:99-108.

31 Schecter A, Paepke O, Ball M, et al. Dioxin concentrations in the blood of workers at municipal waste incinerators. Occup Environ Med 1995;52:385-7.

32 Orloff K, Hewitt D, Metcalf S, et al. Dioxin exposure in a residential community. J Expo Anal Environ Epidemiol 2001;11:352-8.

33 Schuhmacher M, Domingo JL, Llobet JM, et al. Dioxin and dibenzofuran concentrations in blood of a general population from Tarragona, Spain. Chemosphere 1999;38:1123-33.

34 Masuda $Y$, Haraguchi $K$, Kono $S$, et al. Concentrations of dioxins and related compounds and their effects to biochemicals in Fukuoka residents. Organohalogen Compounds 2002;55:267-70. 
35 Jimenez B, Hernandez L, Eljarrat E, et al. Levels of PCDDs, PCDFs and nonortho PCBs in serum of non-exposed individuals living in Madrid (Spain). Chemosphere 1996;33:2403-10.

36 Schecter A, Pavuk M, Paepke O, et al. Dioxin, dibenzofuran, and coplanar PCB levels in Laotian blood and milk from Agent-Orange sprayed and non-sprayed areas, 2001. J Toxicol Environ Health 2003b;66:2067-75.
37 Kang H, Dalager N, Needham L, et al. US army chemical corps Vietnam veteran health study: preliminary results. Chemosphere $2001 ; 43: 943-9$.

38 Jackson WJ, Michalek J. Temporal changes in TCDD levels in 1419 Air Force Vietnam-era veterans not occupationally exposed to herbicides. J Expo Anal Environ Epidemiol 2001;11:50-5.

39 Anonymous. Dioxins and PCBs in the UK Diet: 1997 Total Diet Study (Number 04/00): Food Standards Agency UK, 2000 